Check for updates

Cite this: RSC Adv., 2019, 9, 23045

\title{
Synthesis and antibacterial and antiviral activities of myricetin derivatives containing a 1,2,4-triazole Schiff base $\uparrow$
}

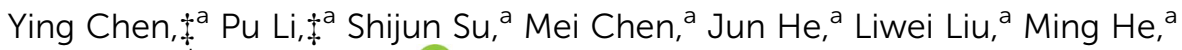 \\ Hua Wang*b and Wei Xue (D)*a
}

A series of novel myricetin derivatives containing a 1,2,4-triazole Schiff base were designed and synthesized. Their structures were systematically characterized using ${ }^{1} \mathrm{H} N M R,{ }^{13} \mathrm{C} N M R$, and HRMS. During antibacterial bioassays, 6f, 6i, and $6 \mathrm{q}$ demonstrated a good inhibitory effect against Xanthomonas axonopodis pv. citri $(X a c)$, with half-maximal effective concentration $\left(E_{50}\right)$ values of $10.0,9.4$, and $8.8 \mu \mathrm{g} \mathrm{mL}^{-1}$, respectively, which were better than those of bismerthiazol $\left(54.9 \mu \mathrm{g} \mathrm{mL} L^{-1}\right)$ and thiodiazole copper $\left(61.1 \mu \mathrm{g} \mathrm{mL}^{-1}\right)$. Note that $6 \mathrm{w}$ demonstrated a good inhibitory effect against Ralstonia solanacearum (Rs) with and $\mathrm{EC}_{50}$ value of $15.5 \mu \mathrm{g} \mathrm{mL}^{-1}$, which was better than those of bismerthiazol $\left(55.2 \mu \mathrm{g} \mathrm{mL}^{-1}\right.$ ) and thiodiazole copper $\left(127.9 \mu \mathrm{g} \mathrm{mL} \mathrm{m}^{-1}\right)$. Similarly, 6a, 6d, and $6 \mathrm{e}$ demonstrated a good inhibitory effect against Xanthomonas oryzae pv. oryzae (Xoo) with $\mathrm{EC}_{50}$ values of $47.1,61.2$, and $61.0 \mu \mathrm{g} \mathrm{mL}^{-1}$, respectively, which were better than those of bismerthiazol $\left(148.2 \mu \mathrm{g} \mathrm{mL}^{-1}\right)$ and thiodiazole copper $\left(175.5 \mu \mathrm{g} \mathrm{mL}^{-1}\right)$. Furthermore, we used scanning electron microscopy (SEM) to study the possible sterilization process of the target compound $6 q$ against $X a c$. The results indicated the possibility of destroying the bacterial cell membrane structure, resulting in an incomplete bacterial structure, and thus achieving inhibition. Furthermore, antiviral bioassays revealed that most compounds exhibited excellent antiviral activity against tobacco mosaic virus (TMV) at a concentration of $500 \mu \mathrm{g} \mathrm{mL}^{-1}$. The results of the molecular docking studies for $6 \mathrm{~g}$ with TMV-CP (PDB code: 1El7) showed that compound $6 \mathrm{~g}$ had partially interacted with TMV-CP. Therefore, mechanistic studies of the action of compound $6 \mathrm{~g}$ could be further studied based on that.

Received 6th July 2019

Accepted 22nd July 2019

DOI: $10.1039 / c 9 r a 05139 b$

rsc.li/rsc-advances canker disease that has significantly impacted production of citrus worldwide. Moreover, Xanthomonas oryzae pv. oryzae (Xoo) is a rod-shaped Gram-negative bacterium causing an average annual loss of $10-50 \%$ in many rice-growing countries. ${ }^{2}$ Therefore, the development of new and highly effective pesticide fungicides and antiviral agents is very important. Flavonoids, or bioflavonoids, which were previously referred to as the basic nucleus structure of 2-phenyl-chromones, and currently referred to as two phenols are a series of compounds in which benzene rings (A and B) are linked to each other via a central three-carbon chain (Fig. 1a and b)., ${ }^{3,4}$

After the initial discovery of flavonoid glycosides in the 1930s, they have been extensively studied by researchers. In fact,
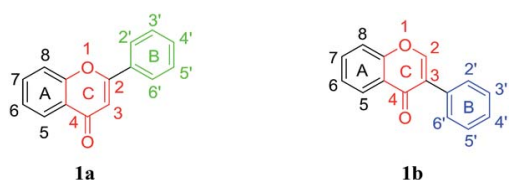

Fig. 1 Core structures of flavones and isoflavones.

\section{in Chinese herbal medicines, flavonoids are very important}

\footnotetext{
${ }^{a}$ State Key Laboratory Breeding Base of Green Pesticide and Agricultural Bioengineering, Key Laboratory of Green Pesticide and Agricultural Bioengineering, Ministry of Education, Center for Research and Development of Fine Chemicals, Guizhou University, Guiyang, 550025, China. E-mail: wxue@gzu.edu.cn

${ }^{b}$ Institute for Plant Protection and Soil Science, Hubei Academy of Agricultural Sciences, Wuhan, 430064, China. E-mail: wanghua4@163.com; Fax: +86-85188292090; Tel: $+86-851-88292090$

$\dagger$ Electronic supplementary information (ESI) available. See DOI: 10.1039/c9ra05139b

$\$$ The first and the second authors contributed equally to this work.
} 
active substances. Flavonoids have antibacterial, ${ }^{5,6}$ antiviral, ${ }^{7,8}$ antitumor, ${ }^{9}$ and antioxidant ${ }^{10}$ activities. Myricetin $\left(3^{\prime}, 4^{\prime}, 5^{\prime}, 3,5,7-\right.$ hexahydroxyflavonol, Myr), similar to bayanone, is an important polyphenol flavonoid that is widely found in many plants. Modern pharmacological studies have confirmed that myricetin has antibacterial, ${ }^{11,12}$ antiviral, ${ }^{13,14}$ antitumor, ${ }^{15}$ antioxidation, ${ }^{16}$ and antiinflammatory ${ }^{\mathbf{1 7}}$ activities. Furthermore, Ruan et al. reported that a series of myricetin derivatives could be used to inhibit plant pathogens. ${ }^{18}$ In our previous study, we demonstrated the synthesis of a series of 3-((5-((4-chlorobenzyl)thio)-1,3,4-thiadiazol-2-yl) methoxy)-5,7-dimethoxy-2-(3,4,5-trimethoxyphenyl)-4H-chromen-4one and $N$-benzyl-2-((5,7-dimethoxy-4-oxo-2-(3,4,5-trimethoxyphenyl)-4H-chromen-3-yl)oxy) acetamide (Fig. 2a and b), both of which exhibited good antibacterial activities. ${ }^{19,20}$

Although there have been a number of studies on myricetin, they are primarily focused on myricetin and its medical applications. Moreover, there have been very few studies on the derivatives of myricetin and their application in pesticides.

In recent decades, heterocyclic compounds have played a critical role for the development of pesticides. In particular, 1,2,4-triazole-based heterocyclic derivatives have become very popular because of their high-efficiency and broad-spectrum biological activity. Similarly, Schiff base compounds have attracted considerable attention because of their unique biological activities, e.g., 1,2,4-triazole Schiff base compounds have both a triazole ring and an imine active fragment of the Schiff base. Therefore, these compounds have a broad spectrum of biological activity such as antibacterial, ${ }^{21,22}$ antitumor, ${ }^{23}$ antiviral, ${ }^{24,25}$ insecticidal, ${ }^{26}$ and weeding. ${ }^{27}$ Jin et al. reported that 1,2,4-triazole Schiff bases could be used to inhibit plant pathogens. $^{28}$

To develop new, highly efficient, environmentally friendly pesticide compounds, myricetin was used as a lead compound to introduce triazole Schiff base structure, a series of myricetin derivatives containing 1,2,4-triazole Schiff base were synthesized and characterized using ${ }^{1} \mathrm{H}$ NMR, ${ }^{13} \mathrm{C}$ NMR, and HRMS. These compounds were then evaluated for their antibacterial and antiviral activities.

\section{Experimental}

\subsection{Methods and materials}

Scheme 1 shows the synthetic route for developing myricetin derivatives containing 1,2,4-triazole Schiff bases. The intermediates $\mathbf{1}, \mathbf{2}, \mathbf{3}, \mathbf{4}$, and 5 were prepared according to previously reported methods. ${ }^{29-31}$
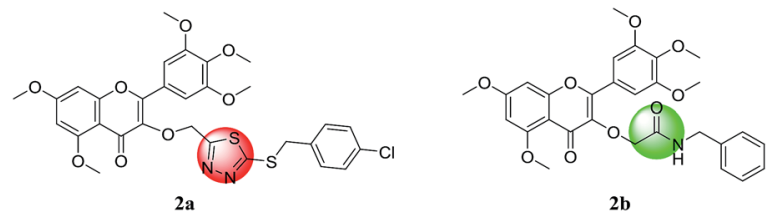

2b

Fig. 2 Compounds previously reported against pathogen.

\subsection{General procedure for preparing the intermediates 1, 2,} 3,4 , and 5

Hydrazine hydrate was dissolved in water at $50{ }^{\circ} \mathrm{C}$ for $0.5 \mathrm{~h}$, followed by the addition of carbon disulfide at $90^{\circ} \mathrm{C}$ for $1 \mathrm{~h}$. The solution was then cooled, followed by crystallization to obtain the intermediate $\mathbf{1}$. Intermediate $\mathbf{1}$ and glacial acetic acid were then refluxed for $4 \mathrm{~h}$, and then cooled to room temperature. Then, the unreacted acetic acid was distilled off and the precipitate washed with water to obtain intermediate 2 . Subsequently, intermediate $\mathbf{2}$ was heated till it completely dissolved in ethanol, and then substituted aldehyde was added for $6 \mathrm{~h}$ to obtain intermediate 3. Myricetin and methyl iodide were stirred at room temperature for $48 \mathrm{~h}$, and then concentrated hydrochloric acid deglucoside was added to obtain intermediate 4 . Finally, the intermediate $\mathbf{4}$ was stirred in DMF at room temperature for $0.5-1 \mathrm{~h}$ and dibromoalkane was added; this reaction was allowed to continue for $12 \mathrm{~h}$ to obtain the intermediate $\mathbf{5}$.

\subsection{General procedure for preparing the target compounds 6a-6w}

The target compounds $\mathbf{6 a - 6 w}$ were synthesized according to previously reported methods, ${ }^{32}$ although certain modifications were made to the preparation process. Intermediate 3 (1.2 $\mathrm{mmol}), \mathrm{K}_{2} \mathrm{CO}_{3}(3 \mathrm{mmol})$, and DMF $(20 \mathrm{~mL})$ were added to a $50 \mathrm{~mL}$ 3-neck round bottom flask equipped with a magnetic stirrer. The mixture was stirred at room temperature for $0.5 \mathrm{~h}$, and then intermediate $5(1.0 \mathrm{mmol})$ was added to the reaction solution with stirring at $100-105{ }^{\circ} \mathrm{C}$ for $6 \mathrm{~h}$. The progress of the reaction was monitored using TLC. Finally, after cooling the reaction mixture to room temperature, $100 \mathrm{~mL}$ of water was added, followed by extraction with dichloromethane $(3 \times 30$ $\mathrm{mL}$ ). The combined organic phases were washed twice with $5 \%$ $\mathrm{NaOH}$, distilled water, and saturated aqueous $\mathrm{NaCl}$. Finally, the solvent was dried, evaporated, and purified (petroleum ether: ethyl acetate $=1: 3, \mathrm{~V} / \mathrm{V})$, and the product was obtained with $40-75 \%$ yield.

\section{Results and discussion}

\subsection{Spectral properties}

${ }^{1} \mathrm{H}$ NMR, ${ }^{13} \mathrm{C}$ NMR and HRMS spectra of all the target compounds are provided in the ESI. $\dagger$ For example, the analysis of the spectral data of $\mathbf{6 a}$ is given below. In the ${ }^{1} \mathrm{H}$ NMR spectrum, $9 \mathrm{H}$ in the $\delta 8.83-7.60 \mathrm{ppm}$ and $\delta 2.44 \mathrm{ppm}$ can be attributed to the hydrogen on the molecular fragment of the 1,2,4-triazole Schiff base, whereas $4 \mathrm{H}$ appearing in the $\delta 7.34-$ $6.48 \mathrm{ppm}$ can be attributed to myricetin. Hydrogens on the benzene ring, $6 \mathrm{H}$ of $\delta 3.99 \mathrm{ppm}, \delta 3.22 \mathrm{ppm}$, and $\delta 2.08-$ $2.02 \mathrm{ppm}$, can be attributed to the methylene hydrogen on the carbon chain, whereas $15 \mathrm{H}$ of $\delta 3.90-3.74 \mathrm{ppm}$ can be attributed to the 5 methoxy group of myricetin's benzene ring. In the HRMS spectrum of the title compound, the characteristic absorption signals of $[\mathrm{M}+\mathrm{H}]^{+}$ions were obtained, which were consistent with their molecular weights. 


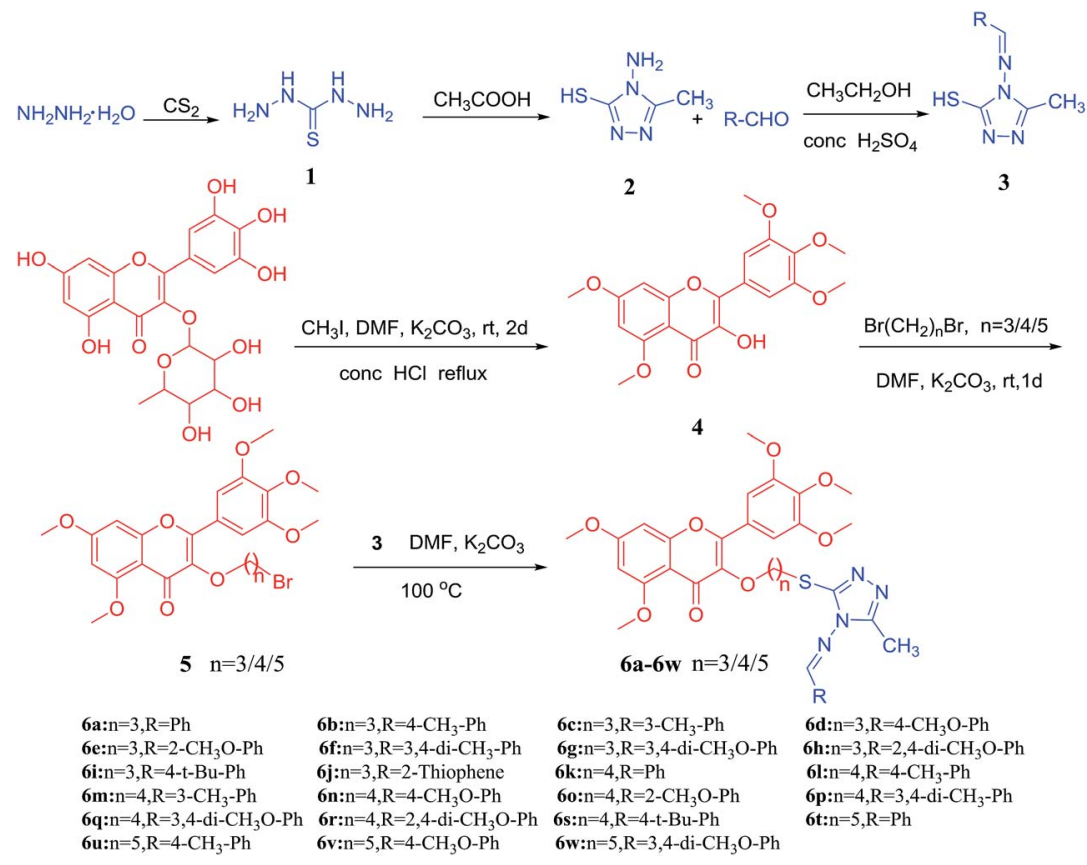

Scheme 1 The synthetic route of the target compounds.

\subsection{Antibacterial activity in vitro}

For determining bioactivity, the target compounds were tested against Xac, Rs, and Xoo using the turbidity method with bismerthiazol, thiadiazole copper, and myricetin being used as control agents. Table 1 lists the antibacterial activities of $\mathbf{6 j}, \mathbf{6 k}$, 6l, 6n, 6q, and 6t against $X a c$ at $100 \mu \mathrm{g} \mathrm{mL}{ }^{-1}$ with the percentage inhibition of $79.6 \%, 79.8 \%, 81.2 \%, 81.8 \%, 84.5 \%$, and $85.8 \%$, respectively, which were better than those of myricetin $(49.4 \%)$, bismerthiazol $(59.5 \%)$, and thiadiazole copper (56.9\%). Note that the percentage inhibition of $\mathbf{6 l , 6 q}$, and $\mathbf{6 t}$ against $\mathrm{Xac}$ at 50 $\mu \mathrm{g} \mathrm{mL}{ }^{-1}$ were $74.9 \%, 75.3 \%$, and $74.9 \%$, respectively, which were better than those of myricetin (40.4\%), bismerthiazol (49.5\%), and thiadiazole copper (47.9\%). Furthermore, 6w showed antibacterial activity against $R s$ at $100 \mu \mathrm{g} \mathrm{mL}^{-1}$ with the percentage inhibition of $83.2 \%$, which was better than those of myricetin (56.4\%), bismerthiazol (61.1\%), and thiadiazole copper $(37.1 \%)$. Similarly, the percentage inhibition of $6 \mathbf{w}$ against $R s$ at $50 \mu \mathrm{g} \mathrm{mL}{ }^{-1}$ was $70.3 \%$, which was better than those of myricetin (43.3\%), bismerthiazol (49.5\%), and thiadiazole copper (17.4\%). Moreover, 6a, 6e, $\mathbf{6 h}$, and $\mathbf{6 w}$ showed antibacterial activities against $X o o$ at $100 \mu \mathrm{g} \mathrm{mL}^{-1}$ with the percentage inhibition of $59.1 \%, 57.1 \%, 57.3 \%$, and $56.5 \%$, respectively, which were better than those of myricetin $(41.4 \%)$, bismerthiazol (47.0\%), and thiadiazole copper (43.2\%). Similarly, the percentage inhibition of compounds $\mathbf{6 a}, \mathbf{6 h}$, and $\mathbf{6 w}$ against $X o O$ at $50 \mu \mathrm{g} \mathrm{mL}{ }^{-1}$ were $51.6 \%, 49.5 \%$, and $47.2 \%$, respectively, which were better than those of myricetin $(32.3 \%)$, bismerthiazol (39.6\%), and thiadiazole copper (38.2\%).

Based on these preliminary results of bioassays, $\mathrm{EC}_{50}$ values of some of the compounds showed good antibacterial activities against Xac, Rs and Xoo as indicated in Tables 2 and 3. As can be seen from Tables 2 and 3, compounds $\mathbf{6 f}, \mathbf{6 i}$, and $\mathbf{6 q}$ showed good inhibitory effects against $\mathrm{Xac}$ with the $\mathrm{EC}_{50}$ values of 10.0, 9.4 , and $8.8 \mu \mathrm{g} \mathrm{mL}^{-1}$, which were better than those of myricetin (107.2 $\left.\mu \mathrm{g} \mathrm{mL}^{-1}\right)$, bismerthiazol $\left(54.9 \mu \mathrm{g} \mathrm{mL}^{-1}\right)$, and thiodiazole copper $\left(61.1 \mu \mathrm{g} \mathrm{mL} \mathrm{mL}^{-1}\right)$. Similarly, 6w demonstrated a good inhibitory effect against $R s$ with an $\mathrm{EC}_{50}$ value of $15.5 \mu \mathrm{g} \mathrm{mL}^{-1}$, which was better than those of myricetin $\left(82.6 \mu \mathrm{g} \mathrm{mL}{ }^{-1}\right)$, bismerthiazol $\left(55.2 \mu \mathrm{g} \mathrm{mL}^{-1}\right)$, and thiodiazole copper $(127.9 \mu \mathrm{g}$ $\mathrm{mL}^{-1}$ ). Moreover, $\mathbf{6 a}, \mathbf{6 d}$, and $\mathbf{6 e}$ demonstrated good inhibitory effects against $\mathrm{Xoo}$ with $\mathrm{EC}_{50}$ values of 47.1, 61.2, and $61.0 \mu \mathrm{g}$ $\mathrm{mL}^{-1}$, which were better than those of myricetin $(222.4 \mu \mathrm{g}$ $\left.\mathrm{mL}^{-1}\right)$, bismerthiazol $\left(148.2 \mu \mathrm{g} \mathrm{mL}^{-1}\right)$, and thiodiazole copper $\left(175.5 \mu \mathrm{g} \mathrm{mL} \mathrm{m}^{-1}\right)$.

\subsection{Structure-activity relationships (SAR) of antibacterial activities}

According to the results in Tables 2 and 3, combined with the activity data analysis of the parent structure of myricetin, the myricetin derivative can be obtained after introducing the 1,2,4triazole Schiff base, which can inhibit biological activity. For example, $\mathbf{6 f}\left(n=3, \mathrm{R}=3,4-\mathrm{di}-\mathrm{CH}_{3}-\mathrm{Ph}\right), \mathbf{6 i}(n=3, \mathrm{R}=4-\mathrm{t}$-Bu-Ph), and $\mathbf{6 q}\left(n=4,3,4\right.$-di- $\left.\mathrm{CH}_{3} \mathrm{O}-\mathrm{Ph}\right)$ demonstrated a good inhibitory effect against $\mathrm{Xac}$ with the $\mathrm{EC}_{50}$ values of $10.0,9.4$, and $8.8 \mu \mathrm{g}$ $\mathrm{mL}^{-1}$, which were better than those of myricetin $(107.2 \mu \mathrm{g}$ $\left.\mathrm{mL}^{-1}\right)$, bismerthiazol $\left(54.9 \mu \mathrm{g} \mathrm{mL}^{-1}\right)$, and thiodiazole copper (61.1 $\left.\mu \mathrm{g} \mathrm{mL}{ }^{-1}\right)$. Similarly, 6w $\left(n=5, \mathrm{R}=3,4\right.$-di- $\left.\mathrm{CH}_{3} \mathrm{O}-\mathrm{Ph}\right)$ demonstrated a good inhibitory effect against $R s$ with $\mathrm{EC}_{50}$ value of $15.5 \mu \mathrm{g} \mathrm{mL}{ }^{-1}$, which was better than those of myricetin $\left(82.6 \mu \mathrm{g} \mathrm{mL}{ }^{-1}\right)$, bismerthiazol $\left(55.2 \mu \mathrm{g} \mathrm{mL} \mathrm{m}^{-1}\right)$, and thiodiazole copper $\left(127.9 \mu \mathrm{g} \mathrm{mL}^{-1}\right)$. Moreover, $6 \mathbf{a}(n=3, \mathrm{R}=\mathrm{Ph}), \mathbf{6 d}(n=3$, $\left.\mathrm{R}=4-\mathrm{CH}_{3} \mathrm{O}-\mathrm{Ph}\right)$, and $6 \mathrm{e}\left(n=3, R=2-\mathrm{CH}_{3} \mathrm{O}-\mathrm{Ph}\right)$ demonstrated good inhibitory effect against $X o o$ with $\mathrm{EC}_{50}$ values of 47.1, 61.2, and $61.0 \mu \mathrm{g} \mathrm{mL} \mathrm{m}^{-1}$, which were better than those of myricetin 
(222.4 $\left.\mu \mathrm{g} \mathrm{mL}^{-1}\right)$, bismerthiazol $\left(148.2 \mu \mathrm{g} \mathrm{mL}^{-1}\right)$, and thiodiazole copper $\left(175.5 \mu \mathrm{g} \mathrm{mL}^{-1}\right)$. According to the results in Tables 2 and 3 , together with the activity data analytical of the parent structure of myricetin, the myricetin derivatives can be obtained after introducing the 1,2,4-triazole Schiff base, which can inhibit biological activity. For example, when $n=3, \mathrm{R}$ is $\mathrm{Ph}, 4-\mathrm{CH}_{3} \mathrm{O}-\mathrm{Ph}$, 2- $\mathrm{CH}_{3} \mathrm{O}-\mathrm{Ph}, 3,4-$ di- $\mathrm{CH}_{3} \mathrm{O}-\mathrm{Ph}$, and 2,4-di- $\mathrm{CH}_{3} \mathrm{O}-\mathrm{Ph}$, the activity of substituted benzene is higher than that of substituted phenylcontaining methoxy compounds. When $n=4, \mathrm{R}$ is $\mathrm{Ph}, 4-$ $\mathrm{CH}_{3} \mathrm{O}-\mathrm{Ph}, 2-\mathrm{CH}_{3} \mathrm{O}-\mathrm{Ph}$, and 3,4-di- $\mathrm{CH}_{3} \mathrm{O}-\mathrm{Ph}$, the activity of substituted phenyl is higher than that of substituted benzene compounds.

To summarize, the derivative obtained by introducing the 1,2,4-triazole Schiff base into the myricetin structure as a lead compound has a good inhibitory activity against plant pathogens and can be used as a potential plant-inhibiting drug.

\subsection{SEM study}

According to the results in Fig. 3A-C, the surface morphology of Xac was observed by scanning electron microscopy (SEM).33,34 Bacterial cells in group (A) were rhabditiform, homogeneous in size, and unbroken in morphology. After treatment with 6q $\left(12.5 \mu \mathrm{g} \mathrm{mL}^{-1}\right)$, cell wall invagination appeared at both ends of the bacterial cells. Moreover, after treatment with 6q $(25 \mu \mathrm{g}$ $\mathrm{mL}^{-1}$ ), the bacterial cell wall showed different degrees of rupture and the cell contents leaked.

\subsection{Antiviral activity of the title compounds against TMV}

As can be seen in Table 4, at a test concentration of $500 \mu \mathrm{g}$ $\mathrm{mL}^{-1}$, the curative, protective, and inactivation activities of the target compounds against tobacco mosaic virus (TMV) were tested. The results showed that both $\mathbf{6 g}$ and $\mathbf{6 j}$ showed a good therapeutic effect on TMV, whereas the percentage inhibition were $52.5 \%$ and $52.4 \%$, respectively, which exceeded those of myricetin (31.6\%) and ribavirin (39.9\%) but close to that of ningnanmycin (52.7\%). Similarly, 6f, 6p, and 6w show a good protective effect on TMV, and their percentage inhibition were $58.7 \%, 57.8 \%$, and $58.0 \%$, respectively, which exceeded those of myricetin $(42.1 \%)$ and ribavirin $(51.8 \%)$ but close to that of ningnanmycin (65.7\%). Furthermore, $6 \mathrm{~g}$ showed a good passivation effect on TMV, and its percentage inhibition was $88.6 \%$, which exceeded those of myricetin (50.9\%) and ribavirin $(73.3 \%)$ but close to that of ningnanmycin $(90.4 \%)$.

Table 1 In vitro antibacterial activity of the target compounds against Xac, Rs and Xoo

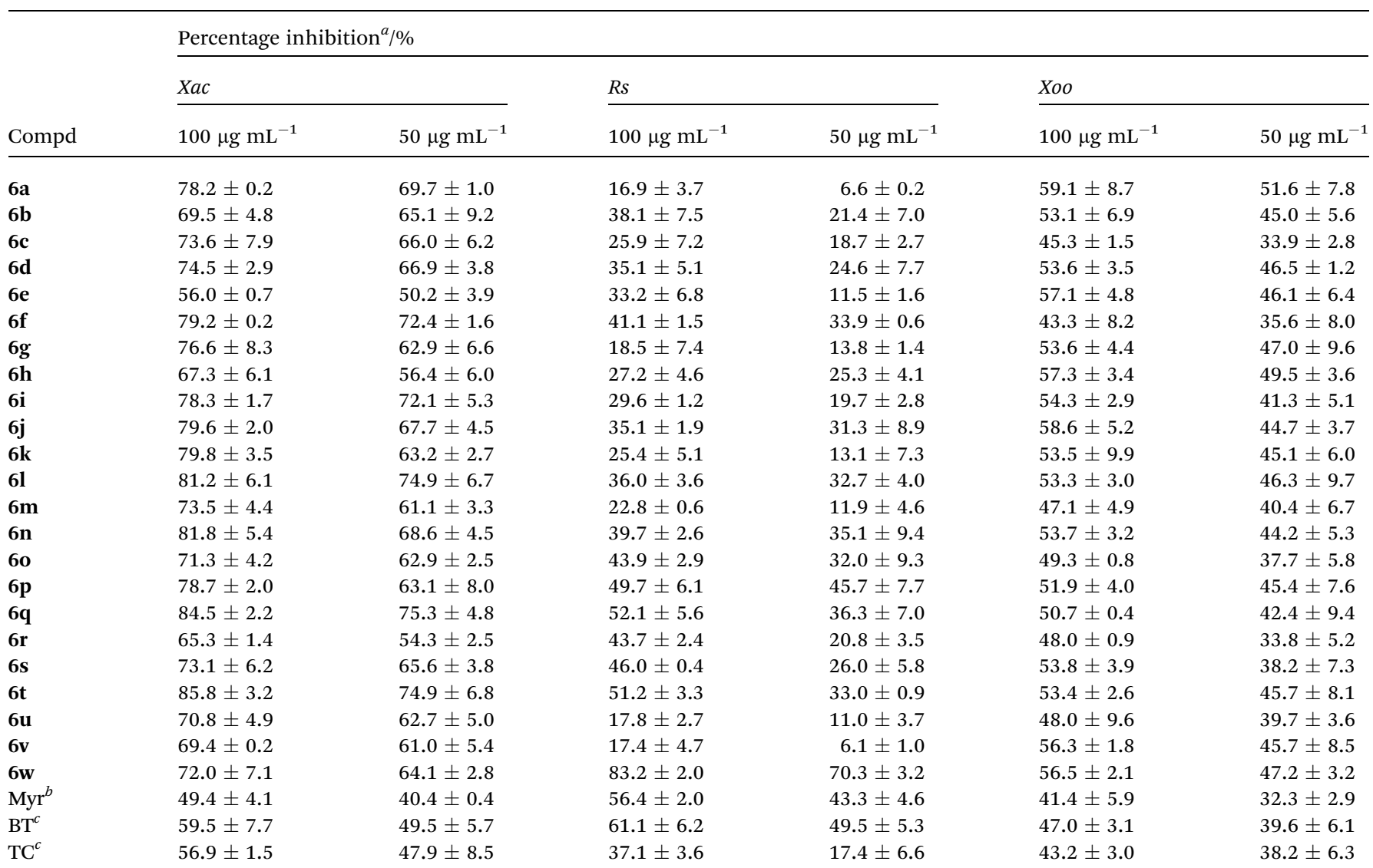

${ }^{a}$ Average of three replicates (temperature: $28 \pm 1{ }^{\circ} \mathrm{C}$, time: $24-48 \mathrm{~h}$ ). ${ }^{b} \mathrm{Myr}$ (myricetin). ${ }^{c} \mathrm{BT}$ (commercial fungicides, bismerthiazol) and TC (thiediazole copper). 
Table 2 In vitro antibacterial $\mathrm{EC}_{50}$ activity value of the target compounds against Xac

\begin{tabular}{|c|c|c|c|c|c|c|}
\hline Compd & $n$ & $\mathrm{R}$ & Toxic regression equation ${ }^{a}$ & $r^{2}$ & $\mathrm{EC}_{50} /\left(\mu \mathrm{g} \mathrm{mL} L^{-1}\right)$ & $\mathrm{pEC}_{50} /(\mu \mathrm{M})$ \\
\hline $6 a$ & 3 & $\mathrm{Ph}$ & $y=0.8044 x+4.1554$ & 0.9961 & $11.2 \pm 3.4$ & 4.8 \\
\hline $6 \mathbf{b}$ & 3 & $4-\mathrm{CH}_{3}-\mathrm{Ph}$ & $y=0.6949 x+4.1397$ & 0.9697 & $17.3 \pm 2.2$ & 4.6 \\
\hline 6d & 3 & $4-\mathrm{CH}_{3} \mathrm{O}-\mathrm{Ph}$ & $y=1.0517 x+3.5664$ & 0.9650 & $23.1 \pm 2.8$ & 4.5 \\
\hline $6 e$ & 3 & $2-\mathrm{CH}_{3} \mathrm{O}-\mathrm{Ph}$ & $y=0.6924 x+3.7991$ & 0.9822 & $54.3 \pm 2.4$ & 4.1 \\
\hline $6 f$ & 3 & 3,4-Di-CH $3-\mathrm{Ph}$ & $y=0.8130 x+4.1875$ & 0.9977 & $10.0 \pm 3.9$ & 4.8 \\
\hline $6 i$ & 3 & $4-t-\mathrm{Bu}-\mathrm{Ph}$ & $y=0.7819 x+4.2398$ & 0.9917 & $9.4 \pm 1.9$ & 4.9 \\
\hline $6 j$ & 3 & 2-Thiophene & $y=0.9335 x+3.8960$ & 0.9642 & $15.2 \pm 2.9$ & 4.6 \\
\hline 6k & 4 & $\mathrm{Ph}$ & $y=0.9655 x+3.7731$ & 0.9334 & $18.7 \pm 0.8$ & 4.6 \\
\hline 61 & 4 & $4-\mathrm{CH}_{3}-\mathrm{Ph}$ & $y=0.9335 x+4.0630$ & 0.9877 & $10.1 \pm 1.1$ & 4.8 \\
\hline $6 m$ & 4 & $3-\mathrm{CH}_{3}-\mathrm{Ph}$ & $y=0.7733 x+4.0122$ & 0.9599 & $18.9 \pm 0.9$ & 4.6 \\
\hline $6 n$ & 4 & $4-\mathrm{CH}_{3} \mathrm{O}-\mathrm{Ph}$ & $y=0.9324 x+3.9636$ & 0.9716 & $12.9 \pm 1.9$ & 4.7 \\
\hline $6 s$ & 4 & $4-t-\mathrm{Bu}-\mathrm{Ph}$ & $y=0.7906 x+4.0584$ & 0.9903 & $15.5 \pm 2.0$ & 4.7 \\
\hline $6 t$ & 5 & $\mathrm{Ph}$ & $y=1.1883 x+3.6956$ & 0.9958 & $12.5 \pm 2.9$ & 4.7 \\
\hline $6 u$ & 5 & $4-\mathrm{CH}_{3}-\mathrm{Ph}$ & $y=0.7831 x+3.9652$ & 0.9780 & $21.0 \pm 1.0$ & 4.5 \\
\hline $6 v$ & 5 & $4-\mathrm{CH}_{3} \mathrm{O}-\mathrm{Ph}$ & $y=0.7105 x+4.0749$ & 0.9998 & $20.5 \pm 2.7$ & 4.5 \\
\hline $6 w$ & 5 & $3,4-\mathrm{Di}^{-} \mathrm{CH}_{3} \mathrm{O}-\mathrm{Ph}$ & $y=0.7706 x+4.0642$ & 0.9814 & $16.4 \pm 1.9$ & 4.7 \\
\hline $\mathrm{Myr}^{b}$ & - & - & $y=0.6520 x+3.6763$ & 0.9838 & $107.2 \pm 1.6$ & - \\
\hline $\mathrm{BT}^{c}$ & - & - & $y=0.8357 x+3.5466$ & 0.9876 & $54.9 \pm 1.4$ & - \\
\hline $\mathrm{TC}^{c}$ & - & - & $y=0.8874 x+3.4149$ & 0.9984 & $61.1 \pm 3.4$ & - \\
\hline
\end{tabular}

${ }^{a}$ Tested and calculated at the drug test concentrations of 100, 50, 25, 12.5, and $6.25 \mu \mathrm{g} \mathrm{mL}{ }^{-1} .{ }^{b}$ Myr (myricetin). ${ }^{c}$ BT (commercial fungicides, bismerthiazol) and TC (thiediazole copper).

\subsection{Structure-activity relationship (SAR) of the title compounds against TMV}

In summary, the introduction of the 1,2,4-triazole Schiff base into the myricetin structure showed a good inhibitory activity against the plant virus. According to the anti-TMV activity data of 1,2,4-triazole Schiff base myricetin derivatives, when $\mathrm{R}=\mathrm{Ph}$, 3,4-di- $\mathrm{CH}_{3}$-Ph, 3,4-di- $\mathrm{CH}_{3} \mathrm{O}-\mathrm{Ph}$, and 2-thiophene, the compounds have good curative and protective activities. For

Table 3 In vitro antibacterial $\mathrm{EC}_{50}$ activity value of the target compounds against $R$ s and $X_{0 O}$

\begin{tabular}{|c|c|c|c|c|c|c|c|}
\hline Bacteria & Compd & $n$ & $\mathrm{R}$ & Toxic regression equation $^{a}$ & $r^{2}$ & $\mathrm{EC}_{50} /\left(\mu \mathrm{g} \mathrm{mL}{ }^{-1}\right)$ & $\mathrm{pEC}_{50} /(\mu \mathrm{M})$ \\
\hline \multirow[t]{3}{*}{ Rs } & $6 w$ & 5 & 3,4-Di- $\mathrm{CH}_{3} \mathrm{O}-\mathrm{Ph}$ & $y=1.0988 x+3.6922$ & 0.9829 & $15.5 \pm 1.3$ & 4.7 \\
\hline & $\operatorname{Myr}^{b}$ & - & - & $y=0.8815 x+3.3101$ & 0.9399 & $82.6 \pm 1.0$ & - \\
\hline & $\mathrm{TC}^{c}$ & - & - & $y=1.3627 x+2.1291$ & 0.9184 & $127.9 \pm 2.5$ & - \\
\hline \multirow[t]{9}{*}{ Xoo } & $6 a$ & 3 & $\mathrm{Ph}$ & $y=0.8103 x+3.6447$ & 0.9958 & $47.1 \pm 2.6$ & 4.1 \\
\hline & $6 b$ & 3 & $4-\mathrm{CH}_{3}-\mathrm{Ph}$ & $y=0.7806 x+3.5304$ & 0.9988 & $76.3 \pm 1.0$ & 3.9 \\
\hline & $6 \mathrm{~g}$ & 3 & 3,4-Di- $\mathrm{CH}_{3} \mathrm{O}-\mathrm{Ph}$ & $y=0.8448 x+3.4411$ & 0.9947 & $70.0 \pm 3.1$ & 4.0 \\
\hline & $6 \mathbf{k}$ & 4 & $\mathrm{Ph}$ & $y=0.6866 x+3.7132$ & 0.9990 & $74.8 \pm 2.6$ & 3.9 \\
\hline & 61 & 4 & $4-\mathrm{CH}_{3}-\mathrm{Ph}$ & $y=0.8236 x+3.4626$ & 0.9798 & $73.6 \pm 3.9$ & 4.0 \\
\hline & $6 \mathrm{~m}$ & 4 & $3-\mathrm{CH}_{3}-\mathrm{Ph}$ & $y=0.9248 x+3.1185$ & 0.9728 & $108.3 \pm 2.0$ & 3.8 \\
\hline & $6 n$ & 4 & $4-\mathrm{CH}_{3} \mathrm{O}-\mathrm{Ph}$ & $y=0.9574 x+3.2088$ & 0.9960 & $74.3 \pm 2.5$ & 4.0 \\
\hline & $6 p$ & 4 & 3,4-Di- $\mathrm{CH}_{3}-\mathrm{Ph}$ & $y=0.1077 x+2.8916$ & 0.9494 & $90.8 \pm 1.8$ & 3.9 \\
\hline & $\mathrm{TC}^{c}$ & - & - & $y=0.5876 x+3.6813$ & 0.9950 & $175.5 \pm 2.1$ & - \\
\hline
\end{tabular}

${ }^{a}$ Tested and calculated at the drug test concentrations of 100, 50, 25, 12.5, and $6.25 \mu \mathrm{g} \mathrm{mL}{ }^{-1} .{ }^{b}$ Myr (myricetin). ${ }^{c}$ BT (commercial fungicides, bismerthiazol) and TC (thiediazole copper). 

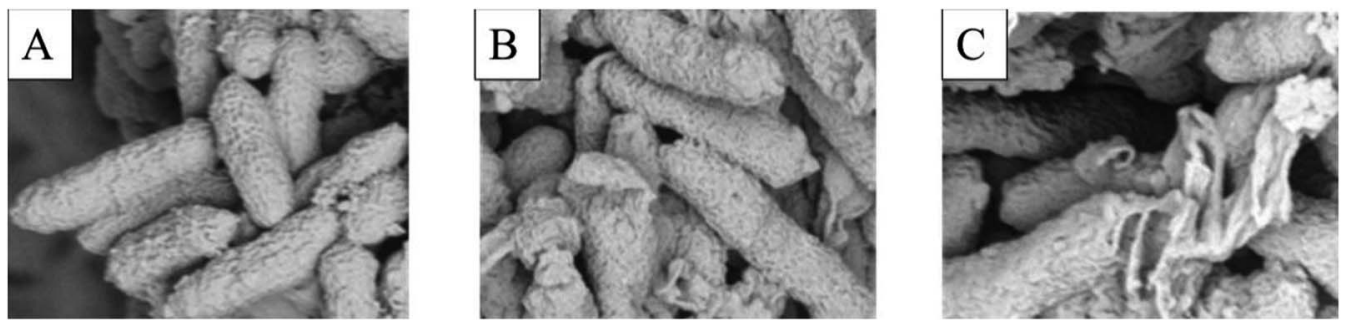

Fig. 3 SEM images for Xac after incubated in different concentration of compound $6 q$. (A) $0 \mu \mathrm{g} \mathrm{mL}{ }^{-1}$, (B) $12.5 \mu \mathrm{g} \mathrm{mL} \mathrm{L}^{-1}$, and (C) $25 \mu \mathrm{g} \mathrm{mL} \mathrm{L}^{-1}$. Scale bar for $(A, B$, and $C$ ) are $2 \mathrm{~mm}$.

example, $\mathbf{6 a}, \mathbf{6 g}, \mathbf{6 j}, \mathbf{6 t}$, and $\mathbf{6 w}$ have a good therapeutic effect on TMV with percentage inhibition of $51.5 \%, 52.5 \%, 52.4 \%, 51.3 \%$, and $51.1 \%$, respectively, which are higher than those of myricetin $(31.6 \%)$ and ribavirin $(39.9 \%)$ but close to that of ningnanmycin (52.7\%). Similarly, 6f, 6g, 6k, 6p, 6t, and 6w have a good protective effect on TMV with percentage inhibition of $58.7 \%, 55.4 \%, 57.2 \%, 57.8 \%, 56.0 \%$, and $58.0 \%$, respectively, which are higher than those of myricetin $(42.1 \%)$ and ribavirin $(51.8 \%)$ but close to that of ningnanmycin $(65.7 \%)$. When $\mathrm{R}=$ 3,4-di- $\mathrm{CH}_{3} \mathrm{O}-\mathrm{Ph}$, the compound showed better passivation activity, e.g., $\mathbf{6 g}$ had a good passivation effect on TMV with an percentage inhibition of $88.6 \%$, which exceeded those of myricetin $(50.9 \%)$ and ribavirin $(73.3 \%)$ but was close to that of ningnanmycin (90.4\%). In summary, when $n=3$, and $n=4$, the
R group is $\mathrm{Ph}, 3,4-\mathrm{di}-\mathrm{CH}_{3}-\mathrm{Ph}, 3,4-\mathrm{di}_{-} \mathrm{CH}_{3} \mathrm{O}-\mathrm{Ph}$, and 2-thiophene, the therapeutic and protective activity of the compounds against tobacco flower leaf virus is superior to the $\mathrm{R}$ group being the other substituent. When $n=3$, and $n=4$, and the R group is 3,4-di- $\mathrm{CH}_{3} \mathrm{O}-\mathrm{Ph}$, the compounds has a relatively good passivating activity against tobacco mosaic virus.

\subsection{Molecular docking of $6 \mathrm{~g}$ and TMV-CP}

Molecular docking studies for $6 \mathrm{~g}$ with TMV-CP (PDB code: $1 \mathrm{EI} 7)^{35,36}$ indicated that the compound was well embedded in the pocket (including residues of TYR139, PRO254, LYS268, ARG134, ASN140, VAL75, etc.) between the two subunits of TMVCP (Fig. 4). It has been reported that these residues played

Table 4 Antiviral activities of the target compounds against TMV in vivo at $500 \mu \mathrm{gL}^{-1}$

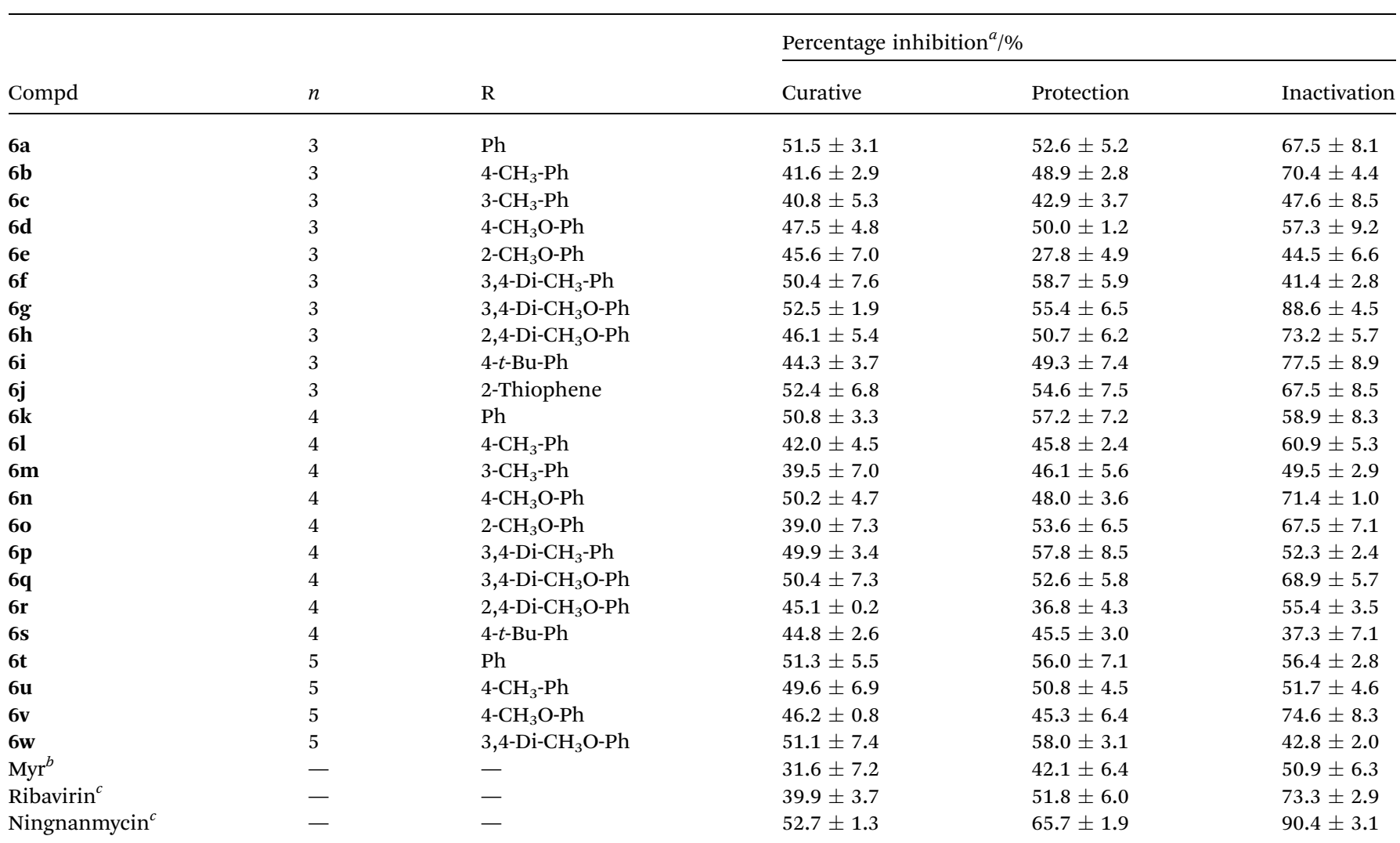

${ }^{a}$ Average of three replicates. ${ }^{b}$ Lead compound myricetin. ${ }^{c}$ Commercial antiviral agents ribavirin and ningnanmycin. 


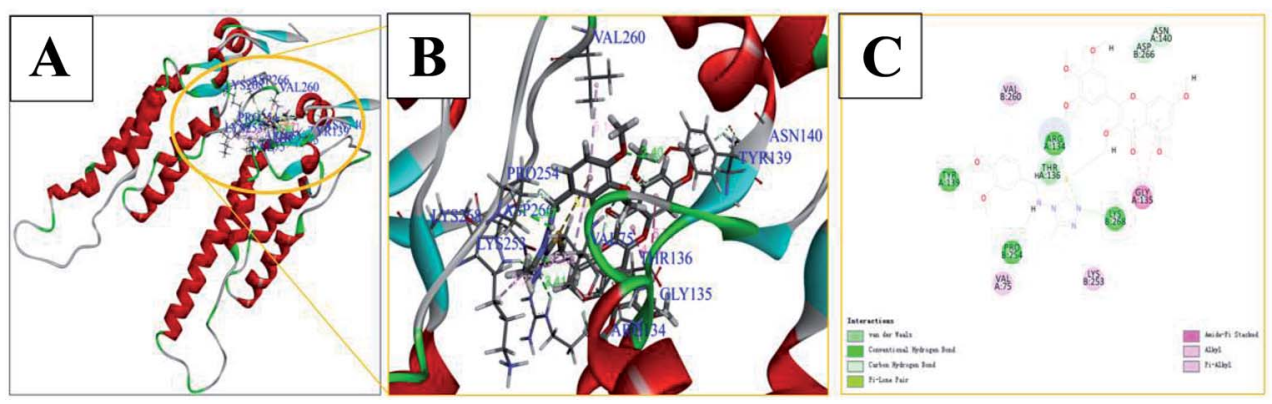

Fig. 4 The binding mode of compound $6 \mathrm{~g}$ docked with TMV-CP.

important roles in the self-assembly of TMV particles. ${ }^{33,35,36}$ For example, LYS268 and TYR139 play continuous hydrophobic interactions in the ring. ${ }^{35}$ In addition, VAL75, VAL260, LYS253, GLY135, ASN140, ASP266 and other subunits of TMV-CP. ${ }^{33,35}$ Moreover, there are also $\pi$-alkyl, alkyl, amide- $\pi$ stacking effects, carbon hydrogen bond between the molecules and the above residues in TMV-CP as depicted in Fig. 4. For example, TYR139, PRO254, LYS268, and ARG134 had strong hydrogen bonds with 6 g $(2.40 \AA, 2.47 \AA, 2.11 \AA$, and $2.41 \AA)$. These interactions between small molecules and TMV-CP are likely to inhibit the interaction of two subunit of TMV-CP, thereby preventing the self-assembly of TMV particle. The results showed that compound $\mathbf{6 g}$ had partially interacted with TMV-CP, and mechanistic studies of the action of compound $\mathbf{6 g}$ could be further studied.

\section{Conclusions}

In this study, using active splicing, a reasonable structural modification of myricetin was undertaken. To design and synthesize a series of myricetin derivatives, an active small molecular group of 1,2,4-triazole Schiff base was introduced into the myricetin structure, and then their biological activities were tested. $\mathbf{6 f}, \mathbf{6 i}$, and $\mathbf{6 q}$ showed a good inhibitory effect against $X a c$ with $\mathrm{EC}_{50}$ values of $10.0,9.4$, and $8.8 \mu \mathrm{g} \mathrm{mL}{ }^{-1}$, which were better than those of bismerthiazol $\left(54.9 \mu \mathrm{g} \mathrm{mL} \mathrm{mL}^{-1}\right)$ and thiodiazole copper $\left(61.1 \mu \mathrm{g} \mathrm{mL}^{-1}\right)$. Moreover, using SEM on the target compound, the antibacterial mechanism against Xac was identified. It was found from the experiment that the cell membrane structure of the bacteria was destroyed, and the bacterial structure changed from the intact form of the blank control (A) to the incomplete form after dosing (B and C). Therefore, this may be the bacteriostatic action of the target compound. Furthermore, antiviral bioassays revealed that most compounds exhibited excellent antiviral activity against TMV at a concentration of $500 \mu \mathrm{g} \mathrm{mL} \mathrm{m}^{-1}$. The results of the molecular docking studies for $\mathbf{6 g}$ with TMV-CP (PDB code: 1EI7) showed that compound $\mathbf{6 g}$ had partially interacted with TMV-CP. Therefore, mechanistic studies of the action of compound $\mathbf{6 g}$ could be further studied based on that. The above biological activity study results demonstrate that the myricetin derivative with the 1,2,4-triazole Schiff base has better biocontrol activity against plant diseases and plant viruses.

\section{Conflicts of interest}

The authors declare that they have no competing interests.

\section{Acknowledgements}

The authors gratefully acknowledge the financial support of the National Nature Science Foundation of China (No. 21867003) and Science Foundation of Guizhou Province (No. 20185781, 20191105).

\section{References}

1 Z. S. Feng and S. J. Gao, Mod. Agric., 2013, 3, 5-6.

2 X. Lv, L. Yang, Z. Fan and X. P. Bao, J. Saudi Chem. Soc., 2018, 22, 101-109.

3 A. L. Simons, M. Renouf, S. Hendrich and P. A. Murphy, J. Agric. Food Chem., 2005, 53, 4258-4263.

4 D. Kim, J. Park, J. Kim, C. Han and C. Lee, J. Agric. Food Chem., 2006, 54, 935-941.

5 I. Oh, W. Y. Yang, S. C. Chung, T. Y. Kim, K. B. Oh and J. Shin, Arch. Pharmacal Res., 2011, 34, 217-222.

6 M. G. Huang, X. H. Ruan, J. P. Zhang, Q. Li, Y. H. Wang, L. J. Chen, C. Zhang, P. Li and W. Xue, Chin. J. Org. Chem., 2017, 37, 2145-2152.

7 W. H. Huang, G. X. Zhou, G. C. Wang, H. Y. Chung, W. C. Ye and Y. L. Li, J. Asian Nat. Prod. Res., 2012, 14, 401-406.

8 J. S. Dong, B. J. Su, H. Oh, B. H. Lee, S. Y. Lee, S. H. Oh, J. Y. Jung and C. S. Choi, Food Control, 2016, 60, 25-30.

9 K. D. Hoang, K. C. Huynh, H. T. Do and T. D. Nguyen, Chem. Pap., 2018, 72, 1399-1406.

10 W. Pietrzak, R. Nowak and M. Olech, Chem. Pap., 2014, 68, 976-982.

11 D. Grenier, H. Chen, L. A. Ben, J. Fournierlarente and M. P. Morin, PLoS One, 2015, 10, e0131758.

12 K. Rashed, A. Ćirić and J. Glamočlija, Ind. Crops Prod., 2014, 59, 210-215.

13 J. T. Ortega, A. I. Suárez, M. L. Serrano, J. Baptista, F. H. Pujol and H. R. Rangel, AIDS Res. Ther., 2017, 14, 57-62.

14 S. Park, J. I. Kim, I. Lee, S. Lee, M. W. Hwang, J. Y. Bae, J. Heo, D. Kim, S. Z. Han and M. S. Park, Biochem. Biophys. Res. Commun., 2013, 440, 14-19. 
15 X. H. Ruan, H. J. Zhao, C. Zhang, L. J. Chen, P. Li, Y. H. Wang, M. He and W. Xue, Chem. J. Chin. Univ., 2018, 39, 1197-1204.

16 V. Chobot and F. Hadacek, Redox Rep., 2011, 16, 242-247.

17 X. Wang, Z. W. Wang, P. S. Sidhu, U. R. Desai and Q. B. Zhou, PLoS One, 2015, 10, e0116409.

18 X. H. Ruan, C. Zhang, S. C. Jiang, T. Guo, R. J. Xia, Y. Chen, X. Tang and W. Xue, Molecules, 2018, 23, 3132-3141.

19 X. M. Zhong, X. B. Wang, L. J. Chen, X. H. Ruan, Q. Li, J. P. Zhang, Z. Chen and W. Xue, Chem. Cent. J., 2017, 11, 106-114.

20 W. Xiao, X. H. Ruan, Q. Li, J. P. Zhang, X. M. Zhong, Y. Xie, X. B. Wang, M. G. Huang and W. Xue, Chem. J. Chin. Univ., 2017, 38, 35-40.

21 F. Zhang, Q. Wen, S. F. Wang, B. Shahla Karim, Y. S. Yang, J. J. Liu, W. M. Zhang and H. L. Zhu, Bioorg. Med. Chem. Lett., 2014, 24, 90-95.

22 K. A. Dilmaghani, F. N. Pur and M. H. Nezhad, Iran. J. Pharm. Res., 2015, 14, 693-699.

23 X. Li, X. Q. Li, H. M. Liu, X. Z. Zhou and Z. H. Shao, Bioorg. Med. Chem. Lett., 2012, 2, 26-30.

24 A. R. Maarouf, A. A. Farahat, K. B. Selim and H. M. Eisa, Med. Chem. Res., 2012, 21, 703-710.

25 Q. Z. Xiong, X. F. Lin, J. H. Liu, L. Bi and X. P. Bao, Chin. J. Org. Chem., 2012, 32, 1255-1260.
26 S. Maddila, R. Pagadala and S. B. Jonnalagadda, J. Heterocycl. Chem., 2015, 52, 487-491.

27 B. L. Wang, Y. X. Shi, Y. Ma, X. H. Liu, Y. H. Li, H. B. Song and Z. M. Li, J. Agric. Food Chem., 2010, 58, 5515-5522.

28 R. Y. Jin, C. Y. Zeng, X. H. Liang, X. H. Sun, Y. F. Liu, Y. Y. Wang and S. Zhou, Bioorg. Chem., 2018, 80, 253-260.

29 C. Y. Liu, Q. Q. Zhao and J. Li, Chem. Reagents, 2001, 23, 344345.

30 D. W. Pan, H. Du, X. Y. Lü and X. P. Bao, Chin. J. Org. Chem., 2016, 36, 818-825.

31 W. Xue, B. A. Song, H. J. Zhao, X. B. Qi, Y. J. Huang and X. H. Liu, Eur. J. Med. Chem., 2015, 97, 155-163.

32 P. Li, Y. Chen, R. J. Xia, T. Guo, M. Zhang, S. C. Jiang, X. Tang, M. He and W. Xue, Chem. J. Chin. Univ., 2019, 40, 909-917.

33 X. Tang, S. J. Su, M. Chen, J. He, R. J. Xia, T. Guo, Y. Chen, C. Zhang, J. Wang and W. Xue, RSC Adv., 2019, 9, 6011-6020.

34 P. Y. Wang, M. W. Wang, D. Zeng, M. Xiang, J. R. Rao, Q. Q. Liu, L. W. Liu, Z. B. Wu, Z. Li, B. A. Song and S. Yang, J. Agric. Food Chem., 2019, 67, 3535-3545.

35 Y. Y. Wang, F. Z. Xu, Y. Y. Zhu, B. A. Song, D. X. Luo, Y. Gang, S. H. Chen, W. Xue and J. Wu, Bioorg. Med. Chem. Lett., 2018, 28, 2979-2984.

36 B. Bhyravbhatla, S. J. Watowich and D. L. D. Caspar, Biophys. J., 1998, 74, 604-615. 